\title{
Robust dicopper(I) $\mu$-boryl complexes supported by a dinucleating naphthyridine-based ligand
}

\author{
Pablo Ríos, ${ }^{a}$ Matthew S. See, ${ }^{a}$ Rex C. Handford ${ }^{a}$ and T. Don Tilley*a \\ Copper boryl species have been widely invoked as reactive intermediates in $\mathrm{Cu}$-catalysed $\mathrm{C}-\mathrm{H}$ borylation reactions, but their \\ isolation and study have been challenging. Use of the robust dinucleating ligand DPFN (2,7-bis(fluoro-di(2-pyridyl)methyl)- \\ 1,8-naphthyridine) allowed for the isolation of two very thermally stable dicopper(I) boryl complexes, [(DPFN)Cu $2(\mu-$ \\ Bpin)][NTf $f_{2}$ (2) and [(DPFN)Cu $\mathrm{Cu}_{2}\left(\mu\right.$-Bcat)][NTf $\left.{ }_{2}\right]$ (4) (pin = 2,3-dimethylbutane-2,3-diol; cat = benzene-1,2-diol). These \\ complexes were prepared by cleavage of the corresponding diborane via reaction with the alkoxide $\left[\left(D_{P F N}\right) C_{2}(\mu-\right.$ \\ $\mathrm{O}^{t} \mathrm{Bu}$ )][NTf $\mathrm{N}_{2}$ (3). Reactivity studies illustrated the exceptional stability of these boryl complexes (thermal stability in solution \\ up to $100^{\circ} \mathrm{C}$ ) and their role in the activation of $\mathrm{C}(\mathrm{sp})-\mathrm{H}$ bonds. X-ray diffraction and computational studies provide a detailed \\ description of the bonding and electronic structures in these species, and suggest that the dinucleating character of the \\ naphthyridine-based ligand is largely responsible for their remarkable stability.
}

\section{Introduction}

Copper-catalysed $\mathrm{C}-\mathrm{H}$ borylation is a powerful tool in organic chemistry due to the stability and versatility of the resulting organoboron species as synthetic building blocks. ${ }^{1}$ This catalysis is thought to involve $\mathrm{Cu}(\mathrm{l})$ boryl $\left(\mathrm{Cu}-\mathrm{BR}_{2}\right)$ complexes as key reactive intermediates. However, the chemistry of $\mathrm{Cu}(\mathrm{I})$ boryls has only recently been observed; while the first proposal of a $\mathrm{Cu}-\mathrm{BR}_{2}$ intermediate stems from a 2000 report by Miyaura ${ }^{2}$ and Hosomi, ${ }^{3}$ the first well-defined $\mathrm{Cu}(\mathrm{I})$ boryl species was described by Sadighi and coworkers in $2005 .{ }^{4}$ Since then, only a few have been isolated. ${ }^{5}$ The paucity of examples is likely due to their inherent instability, given that most of those reported decompose in solution at or below room-temperature to elemental Cu. 4,5 Notably these cases involve monodentate $N$ heterocyclic carbene (NHC) or phosphine supporting ligands. In 2016, Sadighi reported the first dinuclear boryl, $\left\{[(\mathrm{SIPr}) \mathrm{Cu}]_{2}(\mu\right.$-Bcat) $\}\left\{\mathrm{BF}_{4}\right\}$ (Scheme 1, top left, SIPr = 1,3-bis(2,6diisopropylphenyl)imidazolin-2-ylidene), from reaction of $\left\{[(\mathrm{SIPr}) \mathrm{Cu}]_{2}\left(\mu\right.\right.$-OSiMe $\left.\mathrm{OS}_{3}\right)\left\{\mathrm{BF}_{4}\right\}$ with bis(catecholato)diboron $\left(\mathrm{B}_{2} \mathrm{Cat}_{2}\right)$ at $-35^{\circ} \mathrm{C} .^{6}$ The same dicopper cation was obtained by Kleeberg in 2019 upon treatment of mononuclear (SIPr)CuOtBu with $\mathrm{B}_{2} \mathrm{Cat}_{2}$ in THF. Interestingly, mononuclear (SIPr)CuBcat was observed when the reaction was carried out in toluene. ${ }^{7} \mathrm{By}$ modifying the boryl and supporting ligands, the Kleeberg group
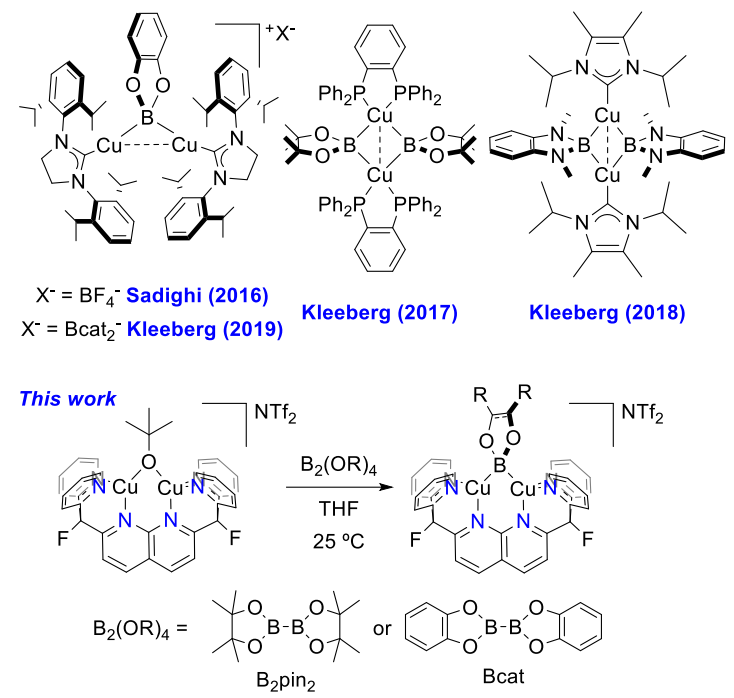

Scheme 1. Examples of dicopper(I) $\mu$-boryl complexes

obtained additional examples of neutral dicopper boryls (Scheme 1). ${ }^{5 c, 8}$ However, the latter species readily decompose in 


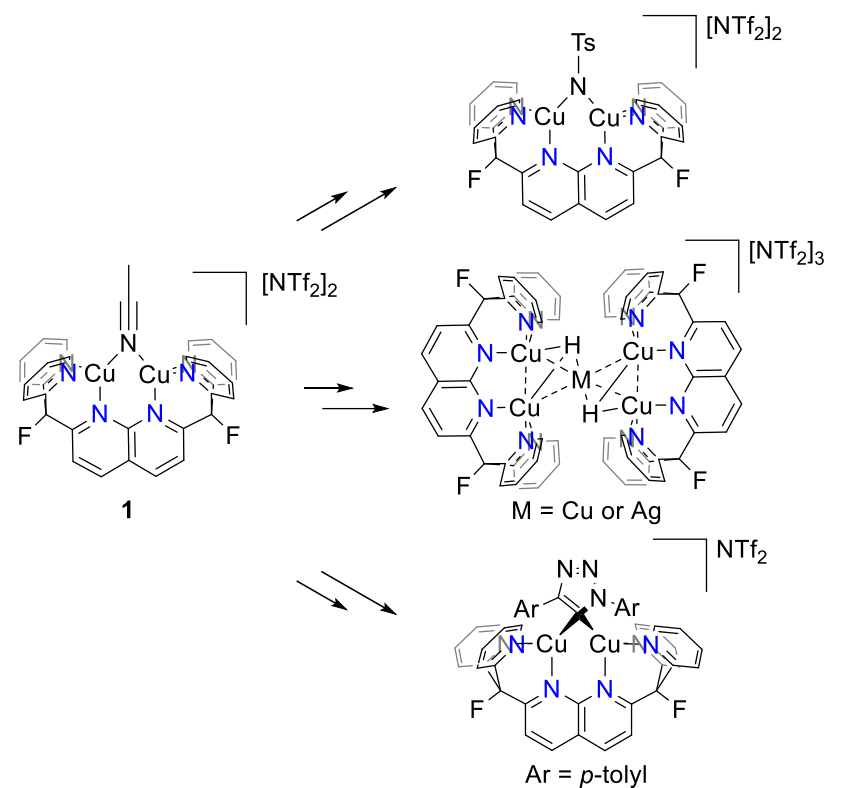

Scheme 2. Examples of detected and/or isolated reactive intermediates containing the $\left[(\mathrm{DPFN}) \mathrm{Cu}_{2}\right]^{\mathrm{n}+}$ scaffold.

solution at or below room-temperature and require storage in the solid-state under an inert atmosphere, complicating their characterisation and study as catalytic intermediates.

Here we report the synthesis and characterisation of two dicopper(I) boryl complexes supported by a 1,8-naphthyridinebased dinucleating ligand. These species are persistent in solution and tolerate heating up to at least $100^{\circ} \mathrm{C}$. In addition, their role in the borylation of $\mathrm{C}(\mathrm{sp})-\mathrm{H}$ bonds and the origins of their stability are described.

\section{Results and discussion}

Previous results from this laboratory established 2,7-bis(fluorodi(2-pyridyl)methyl)-1,8-naphthyridine (DPFN) as an effective platform for stabilisation of bimetallic units. Dicopper(I) [(DPFN) $\left.\mathrm{Cu}_{2}\right]^{+}$complexes, accessed via the convenient starting material $\left[(\mathrm{DPFN}) \mathrm{Cu}_{2}(\mu-\mathrm{NCMe})\right]\left[\mathrm{NTf}_{2}\right]_{2}(\mathbf{1}),{ }^{9}$ exhibit remarkable bimetallic electrophilicity and have allowed for the study of several elusive reactive intermediates such as a dicopper $(I, I I)$ nitrenoid, ${ }^{10}$ pentanuclear metal hydrides, ${ }^{11}$ and an unprecedented dicopper(I) bridging triazolide (Scheme 2). ${ }^{12-14}$ Thus, [(DPFN) $\left.\mathrm{Cu}_{2}\right]^{\text {n+ }}$ seemed a promising framework for the synthesis and stabilisation of dicopper boryl units.
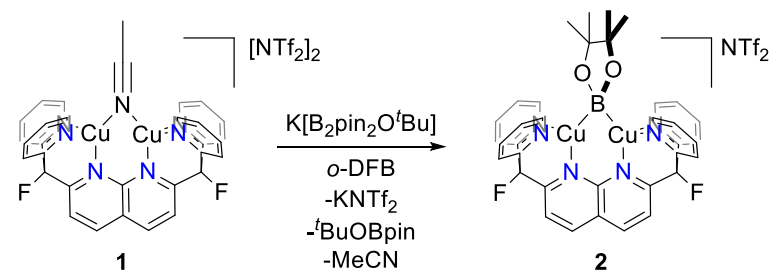

Scheme 3. Initial synthesis of complex 2.

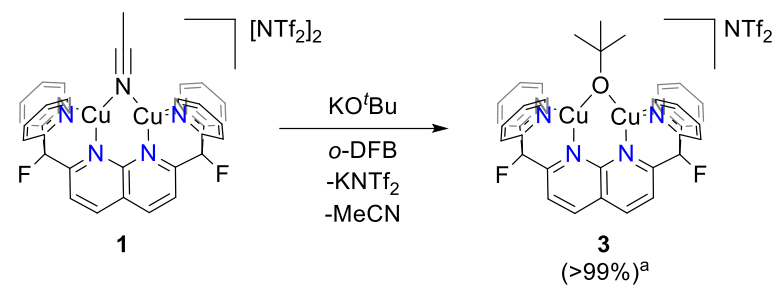

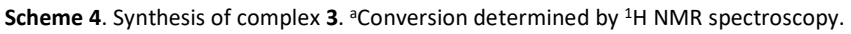

Due to the electrophilic character of $\mathbf{1}$, introduction of a boryl fragment requires an anionic borylation reagent. Whereas few synthons for boryl anions are available, a Lewis base adduct of a tetraalkoxy diboron (with e.g., alkoxide, fluoride or NHC) gives an isolable $\mathrm{sp}^{2}-\mathrm{sp}^{3}$ anionic diboron compound capable of transferring a boryl group to an electrophile under metal-free conditions. ${ }^{15}$ To pursue this possibility, one equivalent of $\mathrm{K}\left[\mathrm{B}_{2} \mathrm{pin}_{2} \mathrm{O}^{t} \mathrm{Bu}\right]$ was added to complex $\mathbf{1}$ in orthodifluorobenzene (o-DFB) at $25{ }^{\circ} \mathrm{C}$ to give a color change from orange to dark green after 3 h. A ${ }^{1} \mathrm{H}$ NMR analysis revealed formation of a single new symmetrical species (2) with a set of resonances corresponding to the DPFN ligand. This was corroborated by ${ }^{19} \mathrm{~F}\left\{{ }^{1} \mathrm{H}\right\}$ NMR spectroscopy, which showed that the singlet at $-175.1 \mathrm{ppm}$ for $\mathbf{1}$ had been replaced by a singlet at $-177.8 \mathrm{ppm}$. The ${ }^{1} \mathrm{H}$ NMR spectrum of the reaction mixture revealed the presence of free $\mathrm{MeCN}$ and ${ }^{t} \mathrm{BuOBpin}$, as well as a singlet at $1.44 \mathrm{ppm}$ associated with 2 . This assignment is supported by the ${ }^{11} \mathrm{~B}$ NMR spectrum containing a single broad resonance for ${ }^{t} \mathrm{BuOBpin}$ at $21.7 \mathrm{ppm}$, in agreement with reported values (Figures S13). ${ }^{16}$ Altogether, these data suggest the formation of boryl complex [(DPFN) $\mathrm{Cu}_{2}\left(\mu\right.$-Bpin)][NTf $\left.f_{2}\right](2$, Scheme 3).

Scale-up of the synthesis of $\mathbf{2}$, or use of THF as solvent led to formation of several side-products, as ascertained by ${ }^{1} \mathrm{H}$ NMR analysis (Figure S14). It was hypothesized that one possible side product could result from the presence of free $\mathrm{KO}^{\mathrm{t}} \mathrm{Bu}$, generated in solution by dissociation from $\mathrm{B}_{2} \mathrm{pin}_{2}$. To test this hypothesis, one equivalent of $\mathrm{KO}^{t} \mathrm{Bu}$ was added to a solution of 1 in $o$-DFB at $25^{\circ} \mathrm{C}$, after which the reaction mixture became dark orange (Scheme 4). The ${ }^{1} \mathrm{H}$ NMR spectrum after $1 \mathrm{~h}$

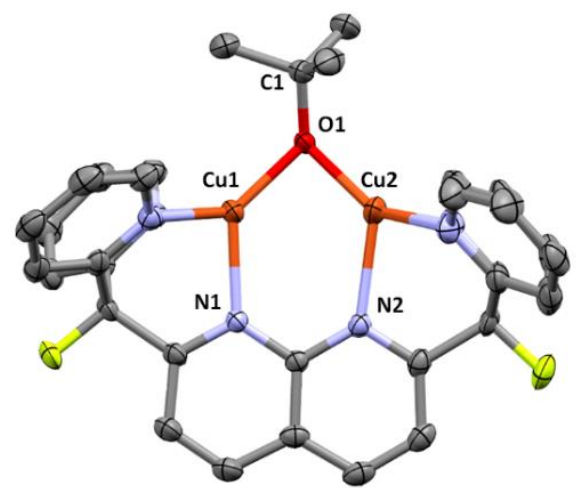

exhibited

Figure 1. Solid-state molecular structure of $\mathbf{3}$ (50\% probability ellipsoids); $\mathrm{H}$ atoms are omitted for clarity. Only the major disorder component of the tert-butoxide fragment is shown. 


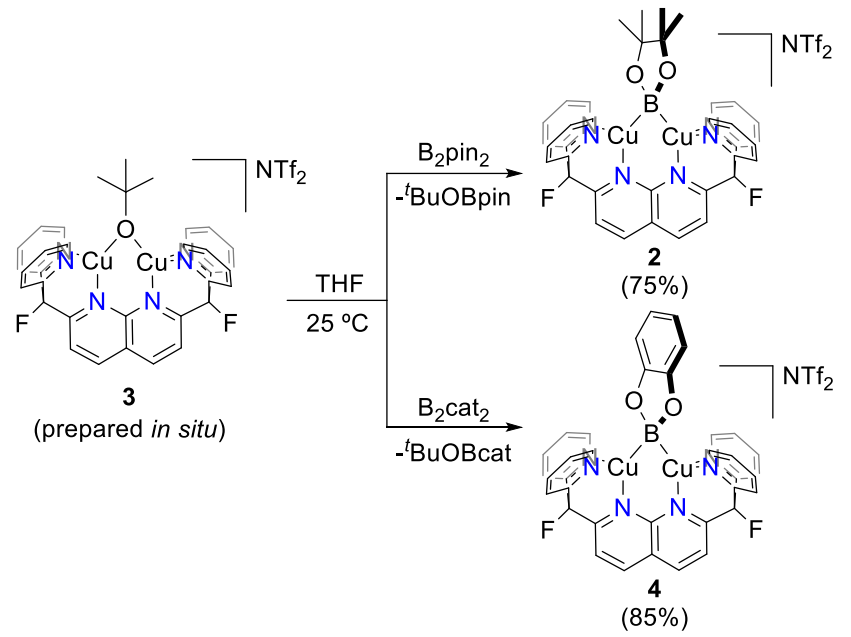

Scheme 5. Synthesis of complexes $\mathbf{2}$ and $\mathbf{4}$ from complex $\mathbf{3}$ (generated in situ). Isolated yields in parentheses.

a new set of resonances resulting from the DPFN ligand, along with a new singlet at $1.76 \mathrm{ppm}$, indicating the clean formation of $\left[(\mathrm{DPFN}) \mathrm{Cu}_{2}\left(\mu-\mathrm{O}^{t} \mathrm{Bu}\right)\right]\left[\mathrm{NTf}_{2}\right]$ (3). The resonances for $\mathbf{3}$ correspond to those of one of the aforementioned sideproducts formed in the synthesis of $\mathbf{2}$, and confirms the release of $\mathrm{KO}^{t} \mathrm{Bu}$ in solution to some extent.

Complex $\mathbf{3}$ was isolated by precipitation from o-DFB or THF with pentane, but removal of volatile components from the resulting powder in vacuo resulted in conversion to an insoluble, intractable material. Nonetheless, dark brown X-ray quality crystals were grown by layer diffusion of $\mathrm{O}\left(\mathrm{SiMe}_{3}\right)_{2}$ into an 0 DFB solution of 3 (generated in solution) after 3 days at $25^{\circ} \mathrm{C} .{ }^{17}$ The solid-state structure, as determined by single crystal diffraction analysis, confirms the proposed assignment (Figure 1). While the $\mathrm{Cu}-\mathrm{O}$ bond distances are similar to those observed in previously reported dicopper complexes containing a 1,8 naphthyridine diphosphine ligand (ca. $1.9 \AA$ A ), ${ }^{18}$ the $\mathrm{Cu} \cdots \mathrm{Cu}$ distance in 3 is much shorter (2.687(1) A vs. 2.9-3.0 $\AA$ ) and the $\mathrm{Cu}-\mathrm{O}-\mathrm{Cu}$ angle is considerably more acute $\left(87.6(2)^{\circ}\right.$ vs 100 $108^{\circ}$ ), indicating a closer metal-metal contact enforced by the dipyridyl (vs. phosphinyl) side-arms. However, the metrical parameters for $\mathbf{3}$ are in good agreement with previous results from this laboratory on a dicopper(I) DPFN complex with a bridging aryloxide ligand. ${ }^{19}$

With a reliable route to complex $\mathbf{3}$, reactions with diboranes were explored. Addition of $\mathrm{B}_{2} \mathrm{pin}_{2}$ to complex $\mathbf{3}$ in THF (prepared in situ from 1) resulted in a dark green solution after stirring at $25^{\circ} \mathrm{C}$ for $15 \mathrm{~h}$. Clean formation of boryl species 2 and ${ }^{\mathrm{t}} \mathrm{BuOBpin}$ (Scheme 5) was observed by ${ }^{1} \mathrm{H},{ }^{19} \mathrm{~F}\left\{{ }^{1} \mathrm{H}\right\}$ and ${ }^{11} \mathrm{~B}\left\{{ }^{1} \mathrm{H}\right\} N M R$ spectroscopy, and no side-products were observed upon increasing the concentration of the reaction solution. Complex 2 was isolated as green crystals by layering pentane over a 0 DFB/THF solution which gave analytically pure $\mathbf{2}$ in 75\% yield. The identity of the complex (Figure 2, top) was confirmed by single-crystal X-ray diffraction. Similarly, $\mathrm{B}_{2} \mathrm{Cat}_{2}$ reacted with complex 3 generated in situ to give the corresponding dicopper(I) boryl complex [(DPFN)Cu $\mathrm{Cu}_{2}\left(\mu\right.$-Bcat)][NTf $\left.{ }_{2}\right](4)$ after 2 $\mathrm{h}$ at $25{ }^{\circ} \mathrm{C}$ (Scheme 5 ), as judged by multinuclear NMR analysis on the resulting purple THF solution. The much shorter reaction time compared to that for the formation of $\mathbf{2}$ might be due to the higher Lewis acidity of $\mathrm{B}_{2} \mathrm{Cat}_{2}$ in comparison to $\mathrm{B}_{2} \mathrm{pin}_{2} .^{20}$ Similar work-up conditions afforded pure 4 as green X-ray quality crystals in $85 \%$ yield (Figure 2, bottom). Unlike most previously described mono- or dicopper boryl complexes, $\mathbf{2}$ and 4 were synthesised and isolated at $25{ }^{\circ} \mathrm{C}$, indicating a considerably higher stability. This is also reflected in mass spectra (Figures S27-S28), which indicate persistence of the dinuclear structures under the ionisation conditions.

The increased stability of these boryl complexes in solution raises interest in their bond metrics compared to those of reported, thermally unstable analogues. However, $\mathbf{2}$ and $\mathbf{4}$ possess geometrical parameters that are within the range of those reported for dicopper $\mu$-boryl complexes. The $\mathrm{Cu}-\mathrm{B}$ bond distances (2.06-2.09 $\AA$ ) are slightly longer than those in cationic $\left\{[(\mathrm{SIPr}) \mathrm{Cu}]_{2}(\mu\right.$-Bcat) $\}\left\{\mathrm{BF}_{4}\right\} \quad$ (ca. $2.05 \AA$ ) $),{ }^{6}$ but are considerably shorter than those in the dinuclear neutral complexes synthesised by Kleeberg and co-workers (> 2.17 $\AA$ )..$^{5 c, 8}$ Similarly, 2 and 4 feature $\mathrm{Cu}-\mathrm{B}-\mathrm{Cu}$ bond angles $\left(\mathrm{ca} .68^{\circ}\right)$ that are more acute than that in Sadighi's dinuclear complex $\left(72.1(2)^{\circ}\right)$ but more obtuse than in Kleeberg's complexes $\left(c a .60^{\circ}\right)$. Finally, the $\mathrm{Cu}$... Cu distances ( $c a .2 .32 \AA$ ) are between those of the cationic

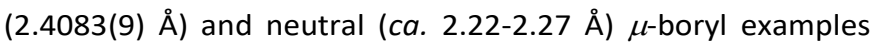
previously reported. Nevertheless, all such distances are significantly shorter than the sum of covalent radii for $\mathrm{Cu}(2.64$ $\AA$ A), ${ }^{21}$ implying that the short metal-metal distances are due to the bridging boryl ligands and/or cuprophilic interactions. ${ }^{22}$ Interestingly, the increased stability of $\mathbf{2}$ and $\mathbf{4}$ in solution does not seem to be attributable to peculiar binding metrics.

The robust character of these boryl species is also manifested in
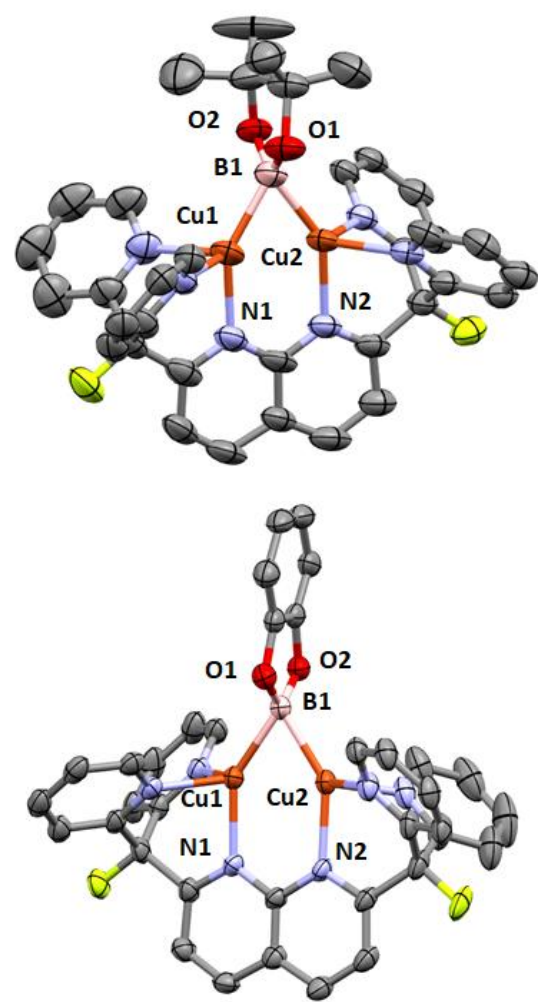

Figure 2. Solid-state molecular structures (50\% probability ellipsoids) of $\mathbf{2}$ (top) and $\mathbf{4}$ (bottom); $\mathrm{H}$ atoms are omitted for clarity. 

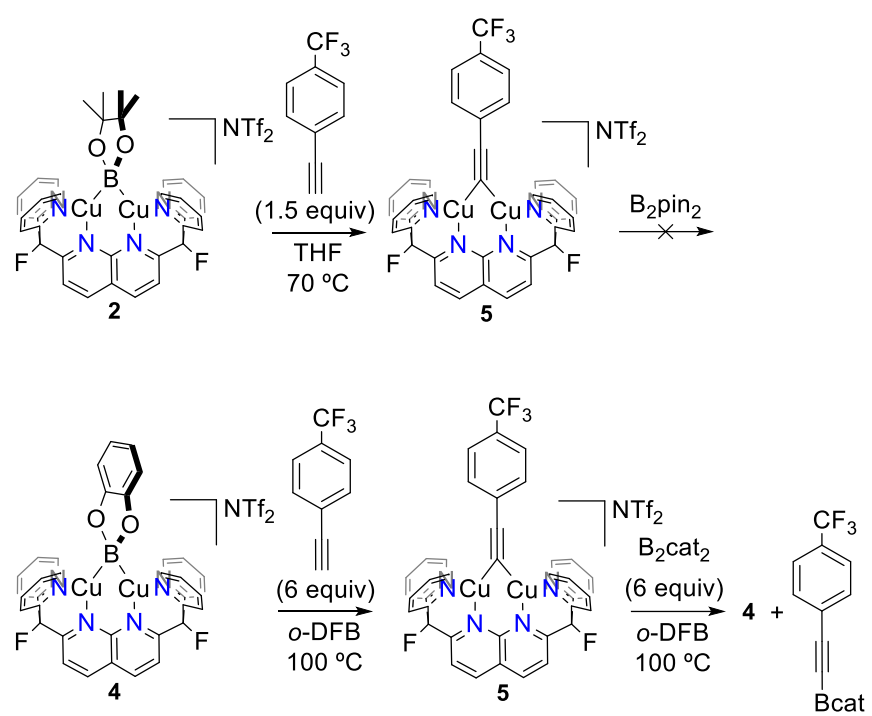

Scheme 6. Reactivity of complexes 2 and $\mathbf{4}$ with $\mathrm{HC} \equiv C\left(p-\mathrm{CF}_{3}-\mathrm{C}_{6} \mathrm{H}_{4}\right)$, yielding complex $\mathbf{5}$, which can further react with $B_{2} c_{2}$ to regenerate boryl species 4 .

their reactivity. Both 2 and $\mathbf{4}$ exhibited no reaction with a number of small molecules including internal alkynes, olefins, silanes, azides or organic molecules possessing weak $\mathrm{C}-\mathrm{H}$ bonds (e.g. fluorene), over a range of reaction conditions (THF or $o^{-}$ DFB as solvents and temperatures up to 70 or $100{ }^{\circ} \mathrm{C}$, respectively; Table S1/Figures S15-S16). In all cases, these bimetallic complexes coexist in solution with the added reagent even at reaction times of $24 \mathrm{~h}$. In contrast to results reported by Kleeberg et al. for dicopper boryls, 2 and $\mathbf{4}$ are inert towards 4iodotoluene. ${ }^{8}$ Aldehydes (1,3,5-trioxane or mesitylaldehyde) did not react with $\mathbf{2}$ or $\mathbf{4}$, in stark contrast to results observed for (IPr)CuBpin (IPr = 1,3-bis(2,6-diisopropylphenyl)imidazol-2ylidene), ${ }^{23}$ demonstrating how nuclearity can have a dramatic influence on the reactivity of boryl derivatives. Warming of $\mathbf{2}$ or 4 to $75{ }^{\circ} \mathrm{C}$ in the presence of either $\mathrm{CO}_{2}$ or $\mathrm{O}_{2}$ gave rise to a complex mixture of products, as shown in the NMR spectra of Figures $\mathrm{S} 17-\mathrm{S} 18$, whereas $\mathrm{H}_{2}$ was unreactive. In contrast, $\mathrm{HC} \equiv \mathrm{C}\left(p-\mathrm{CF}_{3}-\mathrm{C}_{6} \mathrm{H}_{4}\right)$ cleanly reacted with both bridging boryl complexes to yield [(DPFN) $\left.\mathrm{Cu}_{2}\left(\mu-\mathrm{C} \equiv \mathrm{C}\left(\mathrm{C}_{6} \mathrm{H}_{4}\right) \mathrm{CF}_{3}\right)\right]\left[\mathrm{NTf}_{2}\right](\mathbf{5}),{ }^{19}$ as summarised in Scheme 6 (Figures S19-S21). ${ }^{24}$ The increased Lewis basicity of boryl $\mathbf{2}$ compared to $\mathbf{4}$ is evident from the reaction conditions necessary to achieve high (>80\%) conversions: whereas 2 reacted with 1.5 equivalents of alkyne at $70^{\circ} \mathrm{C}$ in 21 hours, boryl 4 required more forcing conditions (6 equivalents of alkyne and warming for 90 hours at $100{ }^{\circ} \mathrm{C}$ ). Interestingly, bridging alkyne 5 further reacted with $\mathrm{B}_{2} \mathrm{cat}_{2}$ (but not with $\mathrm{B}_{2} \mathrm{pin}_{2}$ ) to regenerate Bcat complex 4 (Figure S21), and this reactivity trend is consistent with the observed reactions of $\mathbf{3}$ with diboranes (vide supra). The boron-containing product is not readily identified in the reaction mixture involving $\mathbf{5}$ and $\mathrm{B}_{2} \mathrm{Cat}_{2}$, as its NMR resonances are obscured by the solvent peak. However, filtration of the reaction mixture through silica produced a colorless solid that dissolved in benzene- $d_{6}$ to give a clean spectrum of this product, assigned as the borylated alkyne catBC $\equiv \mathrm{C}\left(p-\mathrm{CF}_{3}-\mathrm{C}_{6} \mathrm{H}_{4}\right)$ (by ${ }^{1} \mathrm{H},{ }^{19} \mathrm{~F}\left\{{ }^{1} \mathrm{H}\right\}$ and ${ }^{11} \mathrm{~B}\left\{{ }^{1} \mathrm{H}\right\} \mathrm{NMR}$ spectroscopy; Figure $\mathrm{S} 23$ ).

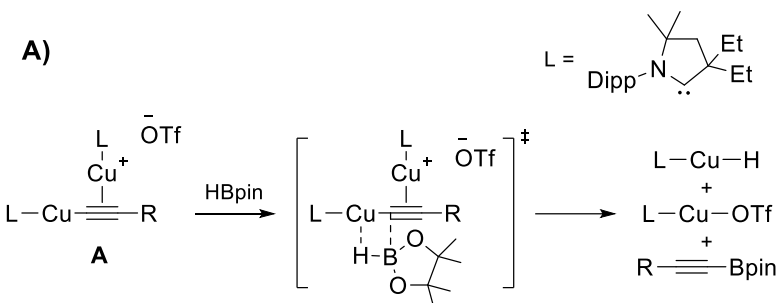

B)

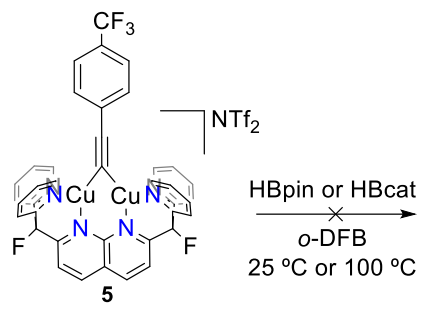

Scheme 7. A) Terminal alkyne dehydrogenative borylation mechanism proposed by Bertrand and coworkers. ${ }^{26}$ B) Control experiments using $\mathbf{5}$ and hydroboranes that rule out alkyne hydroboration processes.

The clean deprotonation of $\mathrm{HC} \equiv \mathrm{C}\left(p-\mathrm{CF}_{3}-\mathrm{C}_{6} \mathrm{H}_{4}\right)$ to give 5 at high temperatures is surprising, given the potential side-reactions that are possible in the presence of free hydroborane, such as alkyne hydroboration ${ }^{25}$ or dehydrogenative borylation. Bertrand and coworkers recently reported catalytic $\mathrm{C}(\mathrm{sp})-\mathrm{H}$ dehydrogenative borylation using carbene-stabilised $\mathrm{Cu}$ complexes, presumably by way of a catalytically active $\sigma, \pi$ dicopper acetylide intermediate A (Scheme 7A). ${ }^{26}$ Unlike species $\mathbf{A}$, the triple bond of bridging alkynyl $\mathbf{5}$ is not engaged in $\pi$-bonding to copper, making it susceptible to hydroboration processes. Control experiments involved the independent synthesis of $\mathbf{5}$ by treating the previously reported bridging phenyl complex $\left[(\mathrm{DPFN}) \mathrm{Cu}_{2}(\mu-\mathrm{Ph})\right]\left[\mathrm{NTf}_{2}\right]^{27}$ with $\mathrm{HC} \equiv \mathrm{C}(p-$ $\left.\mathrm{CF}_{3}-\mathrm{C}_{6} \mathrm{H}_{4}\right)$. Addition of HBpin or HBcat to 5 did not result in reaction at 25 or $100{ }^{\circ} \mathrm{C}$ over $48 \mathrm{~h}$ (Figures S24-25). This divergence in reactivity from that observed by Bertrand et al. could be due to the different binding mode of the alkyne fragment to the dicopper core $(\sigma, \sigma$ vs $\sigma, \pi)$, or to the rigidity imposed by the dinucleating DPFN ligand.

Computational methods were used to gain insights into the unusual robustness of bridging boryls 2 and $\mathbf{4}$. First, steric congestion around the boron atom was quantified by determining its percent buried volume $\left(\% \mathrm{~V}_{\text {bur }}\right)$, described as the volume of a sphere centered on boron that is occupied by the [(DPFN) $\left.\mathrm{Cu}_{2}\right]^{+}$scaffold and the substituents on B (Figures S3134). ${ }^{28,29}$ As expected, $\% V_{\text {bur }}$ values for $\mathbf{2}$ and $\mathbf{4}$ are remarkably large (ca. $80 \%)$, yet intermediate between values observed for unstable species in solution, namely mononuclear (IPr)CuBpin $\left(\% \mathrm{~V}_{\text {bur }}=65.3 \%\right)$. and $\left\{[(\mathrm{SIPr}) \mathrm{Cu}]_{2}(\mu-\mathrm{Bcat})\right\}\left\{\mathrm{BF}_{4}\right\}\left(\% \mathrm{~V}_{\text {bur }}=83.4 \%\right)$.

\begin{tabular}{|c|c|c|c|}
\hline Parameter & $\begin{array}{c}{\left[(\mathrm{DPFN}) \mathrm{Cu}_{2}(\mu\right.} \\
\left.\left.-{ }^{-B p i n}\right)\right]^{+}\end{array}$ & $\begin{array}{c}{\left[(\mathrm{DPFN}) \mathrm{Cu}_{2}(\mu-\right.} \\
{\text { Bcat })]^{+}}^{+}\end{array}$ & $\begin{array}{c}\left\{[(\mathrm{SIPr}) \mathrm{Cu}]_{2}(\mu-\right. \\
\text { Bcat })\}^{+a}\end{array}$ \\
\hline Nat. charge on $\mathrm{Cu}$ & 0.32 & 0.31 & $0.37 / 0.40$ \\
\hline Nat. charge on B & 0.58 & 0.59 & 0.50 \\
\hline Cu-B Bond order & 0.65 & 0.67 & 0.58 \\
\hline $\mathrm{Cu}-\mathrm{Cu}$ Bond order & 0.73 & 0.72 & 0.32 \\
\hline
\end{tabular}

Table 1. Natural charge and bond order values for selected computed dicopper(I) $\mu$-boryl complexes. aValues obtained from reference 6 . 


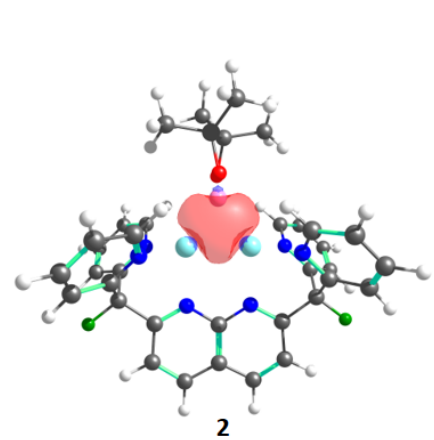

Cu population: $29.67 \%$ (14.91\% Cu1 - $14.76 \%$ Cu2)

B population: $68.12 \%$ (p/s ratio: 0.99)

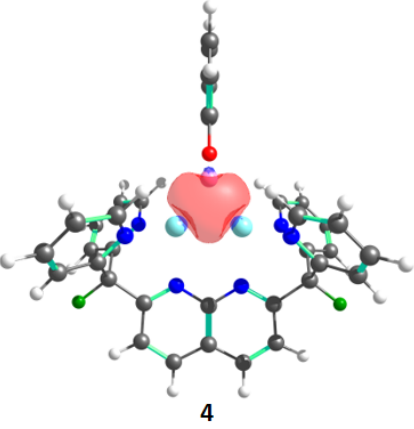

Cu population: $28.60 \%$ (14.40\% Cu1 - $14.20 \%$ Cu2)

B population: $69.46 \%$ ( $\mathrm{p} / \mathrm{s}$ ratio: 0.83 )
Figure 3. Natural Localised Molecular Orbitals (NLMO) of complexes $\mathbf{2}$ and $\mathbf{4}$, depicting $\sigma$-donation of the boryl fragment to the dicopper core.

In light of this, steric hindrance around boron is not likely to be a strong contributor to the stability.

DFT analyses were performed on $\mathbf{2}$ and $\mathbf{4}$ to understand their electronic structures, using the PBEO-D3/6-31g(d,p)/SDD level of theory on the cationic fragments. ${ }^{30}$ The optimised structures were found to be local minima, with geometries in excellent agreement with metrics observed for the solid state structures (Table S2). Natural charges ${ }^{31}$ on $\mathrm{Cu}$ and B reflect minimal differences with those of related cationic systems, as displayed in Table 1. Likewise, Wiberg Bond Order analysis exhibited similar values for all $\mathrm{Cu}-\mathrm{B}$ bonds, albeit the $\mathrm{Cu}$... Cu interactions seem to be stronger in the cationic fragments of $\mathbf{2}$ and $\mathbf{4}$, as expected based on the observed, short $\mathrm{Cu}$... Cu distances. In addition, no bond critical point between the $\mathrm{Cu}$ atoms was observed by QTAIM calculations (Figures S37-38).32,33

Finally, the electron distribution in the $\mathrm{Cu}-\mathrm{B}$ bonds was investigated, since studies attribute the high nucleophilicity and reactivity exhibited by these complexes to the Cu-boryl $\sigma$ bonding electrons. Computational work by Carbó and Fernández in 2012,34 and Sheong and Lin in 2021,35 revealed that the contribution of $\mathrm{B}$-based orbitals to the $\mathrm{M}-\mathrm{BR} \mathrm{R}_{2}$ bond is remarkably high $(c a .70 \% \text {, with a } \mathrm{p} / \mathrm{s} \text { ratio } \approx 0.9)^{36}$ in the case of mononuclear $\mathrm{Cu}$-boryl species, whereas in other examples like $\mathrm{Au}$ - or Pd-boryl compounds, the contribution of $\mathrm{B}$ is around $56 \%$ and $53 \%$, respectively. Therefore, the $\mathrm{Cu}-\mathrm{B}$ bond tends to be substantially more polarised towards the B atom. Natural Localised Molecular Orbital (NLMO) ${ }^{31}$ analysis of $\mathbf{2}$ and $\mathbf{4}$ reveals $\sigma$-donation of the boryl ligand to the empty $4 \mathrm{~s}$ orbitals on the $\mathrm{Cu}$ atoms (as previously observed for [(DPFN)Cu $\left.{ }_{2}\right]^{n+}$ complexes) ${ }^{9}$ with negligible back-donation from the metals to boron. This 3c2e bonding scenario is illustrated in Figure 3 . Surprisingly, the contributions of $\mathrm{Cu}$ - and $\mathrm{B}$-based orbitals to the bonding are almost identical to those previously reported for reactive, mononuclear Cu-boryl complexes (ca. 30\% Cu and 70\% B), with a considerably smaller $\mathrm{p} / \mathrm{s}$ ratio on $\mathrm{B}$ in the case of 4 .

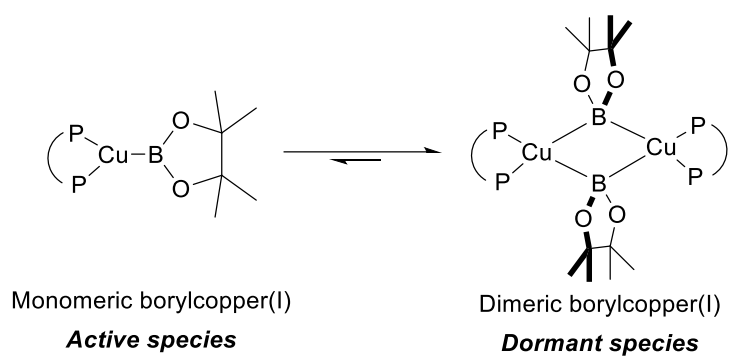

Scheme 8. Dynamic behaviour proposed by Ito and coworkers ${ }^{37}$ between mono- and dinuclear copper boryl species involved in the catalytic borylation of allyl electrophiles.

These data indicate that the extreme stability and chemical inertness of boryls $\mathbf{2}$ and $\mathbf{4}$ in polar solvents does not stem from peculiar geometrical or electronic factors, since these properties are similar to those of much less stable analogues. Rather, the rigid framework imposed by the dinucleating 1,8naphthyridine-based ligand seems to be responsible for the observed stability, by precluding dynamic behaviour in solution that might produce an equilibrium concentration of more reactive, monomeric species. $4,5,7$ This hypothesis finds additional support from a recent study by Ito and coworkers, which concludes that a borylcopper(I) dimer is the dormant species in a catalytic asymmetric borylation process, whereas the mononuclear Cu-boryl complex is the active form of the catalyst (Scheme 8). ${ }^{37}$

\section{Conclusions}

The $\mu$-Ot $\mathrm{Bu}$ complex 3 provides a convenient synthetic pathway to a new type of dicopper boryl derivatives, by a method that may provide more general access to complexes featuring reactive fragments stabilised by a dicopper core. In reactions of 3 with diboranes $B_{2} p n_{2}$ and $B_{2} c_{2} t_{2}$, mild conditions lead to the dinuclear boryl compounds $\mathbf{2}$ and $\mathbf{4}$ by cleavage of a B-B bond. Striking properties of the new boryl complexes reflect a high stability for the $\mathrm{Cu}_{2} \mathrm{~B}$ cores. This stability appears to relate to strong, delocalised bonding across the bridging interaction supported by an effective, rigid dinucleating ligand that suppresses access to reactive monocopper boryl units. These results are therefore consistent with earlier observations concerning the ability of the [(DPFN $\left.) \mathrm{Cu}_{2}\right]^{\text {n+ }}$ platform to stabilise reactive intermediates. Notably, the stability/reactivity balance in $\mu$-boryl dicopper complexes should be tunable by way of modifications to the dinucleating ligand. For example, side arms that enforce a lower coordination number at the metal could lead to higher reactivity, and such possibilities are currently being explored in this laboratory.

\section{Conflicts of interest}

There are no conflicts to declare. 


\section{Acknowledgements}

This work was funded by the US Department of Energy, Office of Science, Office of Basic Energy Sciences, Chemical Sciences, Geosciences, and Biosciences Division under Contract no. DEAC02-05CH11231. This project also received funding from the European Union's Horizon 2020 research and innovation programme under the Marie Skłodowska-Curie grant agreement No 841154 through a fellowship for P.R.. We acknowledge the National Institutes of Health (NIH) for funding the UC Berkeley CheXray X-ray crystallographic facility under grant no. S10- RR027172, the UC Berkeley College of Chemistry NMR facility under Grants SRR023679A, S10OD024998, and 1S10RR016634-01, and the UC Berkeley Molecular Graphics and Computation Facility under grant no. S10OD023532. We thank Dr. Addison N. Desnoyer and T. Alex Wheeler for helpful discussions and Dr. Nicholas S. Settineri for crystallographic assistance.

\section{Notes and references}

1 a) A. Ros, R. Fernández and J. M. Lassaletta, Chem. Soc. Rev., 2014, 43, 3229-3243; b) H. Shinokubo, Proc. Jpn. Acad., Ser. B. 2014, 90, 1-11; c) H. Yoshida, ACS Catal., 2016, 6, 1799-1811; d) D. Hemming, R. Fritzmeier, S. A. Westcott, W. L. Santos and P. G. Steel, Chem. Soc. Rev., 2018, 47, 7477-7494; e) S. A. Iqbal, J. Pahl, K. Yuan and M. J. Ingleson, Chem. Soc. Rev., 2020, 49, 4564-4591.

2 K. Takahashi, T. Ishiyama and N. Miyaura, Chem. Lett., 2000, 29, 982-983.

3 H. Ito, H. Yamanaka, J-I. Tateiwa and A. Hosomi, Tetrahedron Lett., 2000, 41, 6821-6825.

4 D. S. Laitar, P. Müller and J. P. Sadighi, J. Am. Chem. Soc., 2005, 127, 17196-17197.

5 Examples of mononuclear Cu-boryl species unstable in solution: a) K. Semba, M. Shinomiya, T. Fujihara, J. Terao and Y. Tsuji, Chem. Eur. J., 2013, 19, 7125-7132; b) A. J. Jordan, P. K. Thompson and J. P. Sadighi, Org. Lett., 2018, 20, 5242-5246; c) C. Kleeberg and C. Borner, Organometallics, 2018, 37, 41364146; d) W. Drescher, C. Borner and C. Kleeberg, New J. Chem., 2021, 45, 14957-14964. Some examples stable in solution involve the use of apolar solvents such as benzene and/or nitrogen atoms adjacent to boron, see for example: e) Y. Segawa, M Yamashita and K. Nozaki, Angew. Chem. Int. Ed., 2007, 46, 6710-6713; f) T. Kajiwara, T. Terabayashi, M. Yamashita and K. Nozaki, Angew. Chem. Int. Ed., 2008, 47, 6606-6610; g) C. Borner and C. Kleeberg, Eur. J. Inorg. Chem., 2014, 2486-2489; h) T. M. H. Downie, R. S. C. Charman, J. W. Hall, M. F. Mahon, J. P. Lowe and D. J. Liptrot, Dalton Trans., 2021, 50, 16336-16342.

6 C. M. Wyss, J. Bitting, J. Bacsa, T. G. Gray and J. P. Sadighi, Organometallics, 2016, 35, 71-74.

7 W. Drescher and C. Kleeberg, Inorg. Chem., 2019, 58, 82158229.

8 C. Borner, L. Anders, K. Brandhorst and C. Kleeberg, Organometallics, 2017, 36, 4687-4690.

9 A. N. Desnoyer, A. Nicolay, P. Rios, M. S. Ziegler and T. D. Tilley, Acc. Chem. Res., 2020, 53, 1944-1956.

10 A. N. Desnoyer, A. Nicolay, M. S. Ziegler, K. V. Lakshmi, T. R. Cundari and T. D. Tilley, J. Am. Chem. Soc., 2021, 143, 71357143.

11 A. N. Desnoyer, A. Nicolay, M. S. Ziegler, N. A. Torquato and T. D. Tilley, Angew. Chem. Int. Ed., 2020, 59, 12769-12773.
12 M. S. Ziegler, K. V. Lakshmi and T. D. Tilley, J. Am. Chem. Soc., 2017, 139, 5378-5386

13 B. F. Straub, Chem. Commun., 2007, 3868-3870.

14 B. T. Worrell, J. A. Malik and V. V. Fokin, Science, 2013, 340, 457-460.

15 Inspiration came from a) S. Pietsch, E. C. Neeve, D. C. Apperley, R. Bertermann, F. Mo, D. Qiu, M. S. Cheung, L. Dang, J. Wang, U. Radius, Z. Lin, C. Kleeberg and T. B. Marder, Chem. Eur. J., 2015, 21, 7082-7099. Recent reviews on $\mathrm{sp}^{2}$-sp ${ }^{3}$ anionic diboranes can be found in b) R. D. Dewhurst, E. C. Neeve, H. Braunschweig and T. B. Marder, Chem. Commun., 2015, 51 9594-9607; c) J. J. Carbó and E. Fernández, Chem. Commun., 2021, 57, 11935-11947.

16 a) E. A. Romero, J. L. Peltier, R. Jazzar and G. Bertrand, Chem. Commun., 2016, 52, 10563-10565; b) C. Kim, B. Roh and H. G. Lee, Chem. Sci., 2021, 12, 3668-3673.

17 The formation of an insoluble material after exposing complex 3 to vacuum prevented the synthesis of analytically pure solid samples of this compound.

18 E. Kounalis, M. Lutz and D.L.J. Broere, Chem. Eur. J., 2019, 25, 13280-13284.

19 M. S. Ziegler, N. A. Torquato, D. S. Levine, A. Nicolay, H. Celik and T. D. Tilley, Organometallics, 2018, 37, 2807-2823.

20 L. Dang, H. Zhao, Z. Lin and T. B. Marder, Organometallics, 2008, 27, 1178-1186.

21 B. Cordero, V. Gómez, A. E. Platero-Prats, M. Revés, J. Echeverría, E. Cremades, F. Barragán and S. Álvarez, Dalton Trans., 2008, 2832-2838.

22 N. V. S. Harisomayajula, S. Makovetskyi and Y-C. Tsai, Chem. Eur. J. 2019, 25, 8936-8954.

23 D. S. Laitar, E. Y. Tsui, J. P. Sadighi, J. Am. Chem. Soc., 2006, 128, 11036-11037.

24 Concomitant formation of HBpin is observed in the case of complex $\mathbf{2}$. In the case of $\mathbf{4}, \mathrm{HBcat}$ seems to decompose over time to catBOBcat under the reaction conditions. This has been confirmed by warming $\mathrm{HBcat}$ in $\mathrm{o}$-DFB at $100{ }^{\circ} \mathrm{C}$ (see Figures S22 and S26 for more information).

25 S. K. Bose, L. Mao, L. Kuehn, U. Radius, J. Nekvinda, W. L. Santos, S. A. Westcott, P. G. Steel and T. B. Marder, Chem. Rev., 2021, 121, 13238-13341.

26 E. A. Romero, R. Jazzar and G. Bertrand, Chem. Sci., 2017, 8, 165-168. Species A was previously isolated, see L. Jin, D. R. Tolentino, M. Melaimi and G. Bertrand, Sci. Adv. 2015, 1, e1500304.

27 M. S. Ziegler, D. S. Levine, K. V. Lakshmi and T. D. Tilley, J. Am. Chem. Soc., 2016, 138, 6484-6491.

28 A. Poater, F. Ragone, S. Giudice, C. Costabile, R. Dorta, S. P. Nolan and L. Cavallo, Organometallics, 2018, 27, 2679-2681.

29 SambVca 2.1 was used to calculate $\% V_{\text {bur: }}$ L. Falivene, Z. Cao, A. Petta, L. Serra, A. Poater, R. Oliva, V. Scarano and L. Cavallo, Nat. Chem., 2019, 11, 872-879.

30 The calculations were performed with the Gaussian 16 program: Gaussian 16, Revision A.03, Gaussian, Inc. Wallingford CT, 2016. The full Gaussian citation can be found in the ESI.

31 NBO Version 3.1, E. D. Glendening, A. E. Reed, J. E. Carpenter, and F. Weinhold.

32 R. F. W. Bader, Atom in Molecules: A Quantum Theory; Oxford University Press: Oxford, U.K., 1995.

33 Previous work in this laboratory demonstrated the presence of a Bond Critical Point (BCP) between the $\mathrm{Cu}$ atoms in a complex with a longer $\mathrm{Cu} \cdots \mathrm{Cu}$ distance $(2.4457(4) \AA)$, suggesting a stronger cuprophilic interaction. See T. C. Davenport and T.D. Tilley, Angew. Chem. Int. Ed., 2011, 50, 12205-12208.

34 J. Cid, J. J. Carbó and E. Fernández, Chem. Eur. J., 2012, 18, 12794-12802. 
35 X. Guo, T. Yang, F. K. Sheong and Z. Lin, ACS Catal., 2021, 11, 5061-5068.

36 The $p / s$ ratio also gives an idea of the nucleophilicity of a $M$ boryl bond. A boryl ligand with more $p$ character on $B$ will donate more electron density to the metal, making the $M-B$ bond stronger. On the contrary, a boryl ligand with more $S$ character on $\mathrm{B}$ will polarise the $\mathrm{M}-\mathrm{B}$ bond towards $\mathrm{B}$. For more information, see reference 34 or J. Zhu, Z. Lin and T. B. Marder, Inorg. Chem., 2005, 44, 9384-9390.

$37 \mathrm{H}$. Iwamoto, Y. Ozawa, Y. Takenouchi, T. Imamoto and H. Ito, J. Am. Chem. Soc., 2021, 143, 6413-6422. 